\title{
Evolution of Risk Factors for Atherosclerotic Cardiovascular Events in Systemic Lupus Erythematosus: A Longterm Prospective Study
}

\author{
Konstantinos Tselios, Dafna D. Gladman, Jiandong Su, Olga Ace, and Murray B. Urowitz
}

\begin{abstract}
Objective. We previously reported the effect of certain factors on cardiovascular disease (CVD) in 250 women with systemic lupus erythematosus (SLE) followed for 8 years. The aim of this study was to delineate their evolution after 15 years of followup.

Methods. There were 210 women with SLE and 138 age-matched healthy women available for analysis after 15 years. Cardiovascular events (CVE) included angina pectoris, myocardial infarction (fatal and nonfatal), transient ischemic attack, and stroke (fatal and nonfatal). Analysis was performed with SAS 9.3 software; $\mathrm{p}<0.05$ was considered significant.

Results. CVE occurred in 41/210 patients (19.5\%) and 9/138 controls (6.5\%), most of them in the second part (2008-2015) of the study $(24 / 210,11.4 \%$ vs 17/241, 7.1\% in SLE group). Coronary artery disease was more common in patients $(32 / 210,15.2 \%$ vs $5 / 138,3.6 \%, p=0.0041)$. There was no significant difference for cerebrovascular disease $(10 / 210,4.8 \%$ vs $3 / 138,2.2 \%, p=0.213)$. SLE was the most prominent CVE predictor in the first 8 years (HR 2.8, 95\% CI 1.3-6.3). Hypertension and diabetes were more frequent in patients who developed CVE during the second half of the study. Thirty-one deaths occurred in patients with SLE (10 because of CVD) and 6 in controls (none because of CVD).

Conclusion. The relative importance of atherosclerotic risk factors is significantly differentiated over time in SLE. Disease-related factors seem to dominate CV risk during the early stages while traditional factors, partially related to corticosteroid treatment, play a significant role later in the disease course. (First Release November 1 2017; J Rheumatol 2017;44:1841-9; doi:10.3899/jrheum.161121)
\end{abstract}

Key Indexing Terms:

SYSTEMIC LUPUS ERYTHEMATOSUS RISK FACTORS

\begin{abstract}
Beginning with case series in 1976, it has become well established that there is an increased incidence of premature coronary artery disease (CAD) in patients with systemic lupus erythematosus (SLE) as compared to the general population $^{1}$. Large cohort studies in Toronto ${ }^{2}$, Pittsburgh ${ }^{3}$, and Baltimore ${ }^{4}$ have all shown a high prevalence of atherosclerotic cardiovascular events (CVE) in these patients, ranging from $6.6 \%$ to $10.9 \%$. In addition, CVE in patients
\end{abstract}

From the Centre for Prognosis Studies in Rheumatic Diseases, Toronto Lupus Clinic, University Health Network, Toronto, Ontario, Canada.

Dr. Tselios is financially supported by the Geoff Carr Fellowship from Lupus Ontario.

K. Tselios, MD, PhD, Centre for Prognosis Studies in Rheumatic Diseases, Toronto Lupus Clinic, University Health Network; D.D. Gladman, MD,

FRCPC, Centre for Prognosis Studies in Rheumatic Diseases, Toronto Lupus Clinic, University Health Network; J. Su, MB, BSc, Health Care and Outcomes Research, Toronto Western Hospital; O. Ace, MD,

University of Toronto Lupus Clinic; M.B. Urowitz, MD, FRCPC, Centre

for Prognosis Studies in Rheumatic Diseases, Toronto Lupus Clinic,

University Health Network.

Address correspondence to Dr. M.B. Urowitz, University of Toronto Lupus Clinic, Centre for Prognosis Studies in the Rheumatic Diseases, Toronto Western Hospital, 399 Bathurst St. 1E-410B, Toronto, Ontario M5T 2S8, Canada.E-mail:m.urowitz@utoronto.ca

Accepted for publication July 28, 2017.

\section{CARDIOVASCULAR DISEASE MORTALITY}

with SLE occur at a significantly younger age than in population controls, with many events in the fourth and fifth decade of life rather than the general population peak of 65-74 years ${ }^{5}$. Apart from CVE, new imaging modalities such as carotid Doppler ultrasound and coronary artery computed tomography have demonstrated an increased amount of carotid plaque and coronary artery calcification in patients with SLE compared to matched healthy controls, adding further evidence for the acceleration of the atherosclerotic process in $\mathrm{SLE}^{6,7,8,9}$. Further, coronary angiography studies have demonstrated that SLE is associated with increased CAD severity because SLE patients with a mean age of 49 years had comparable coronary atherosclerotic burden to non-SLE patients with a mean age of 70 years ${ }^{10}$.

Both traditional [e.g., age, hypertension (HTN), diabetes mellitus (DM), dyslipidemia, smoking] and disease-related risk factors (e.g., disease activity and cumulative damage, renal involvement, inflammatory mediators, medications) have been implicated in increasing the atherosclerotic risk in $\mathrm{SLE}^{11}$. The former cannot fully explain the increased risk for CAD in patients with SLE because it has been demonstrated that there is still an excess relative risk of 7.5 (95\% CI 5.1-10.4) ${ }^{12}$. Research has shown that novel factors such as

Personal non-commercial use only. The Journal of Rheumatology Copyright (c) 2017. All rights reserved. 
homocysteine, C-reactive protein (CRP), proinflammatory high-density lipoprotein (HDL), and certain autoantibodies are also implicated in the accelerated atherosclerotic process in $\mathrm{SLE}^{13}$.

The Toronto Risk Factor Study began in 1998 and recruited 250 female patients with SLE and 250 age-matched healthy women (controls) from a Family Practice Clinic to prospectively study risk factors and ascertain outcomes for $\mathrm{CVE}^{14}$. Subjects in both groups had a low 10-year CAD risk according to the Framingham Risk Score (FRS). After 7 years of followup, patients with SLE were found to have a significantly higher rate of clinical $\mathrm{CAD}^{15}$. Multivariate analysis revealed that SLE itself, older age at study entry, and triglycerides (TG) above $2.8 \mathrm{mmol} / \mathrm{l}$ were predictive of CAD; other risk factors had no significant effect.

The aim of our present study was to further assess the incidence of atherosclerotic CVE in the initial cohort after 15 years of followup and evaluate any differences in the relative importance of traditional and SLE-related risk factors over time. Particular emphasis was given to identify the factors implicated in CVE development later in disease course.

\section{MATERIALS AND METHODS}

Patients with SLE. Patients with SLE were recruited from the University of Toronto Lupus Clinic and followed prospectively. Clinical and laboratory information, including therapy and relevant outcome measures, are systematically collected at 2- to 6-month intervals and stored in an electronic database. Detailed description of the initial 250 patients has been published elsewhere ${ }^{14,15}$. Briefly, women with SLE attending the Lupus Clinic from May 1998 to June 2000 were invited to participate in the study. All patients (mean disease duration $13.7 \pm 9.7$ yrs) fulfilled the 1997 American College of Rheumatology classification criteria $(n=241)$ or 3 criteria and a confirmatory skin or renal biopsy $(n=9)^{16}$. Patients were excluded if they had a history of myocardial infarction (MI), angina pectoris, stroke, transient ischemic attack (TIA), and/or peripheral vascular disease.

Controls. Two hundred and fifty age-matched women who were attending the Family Practice Unit at the same hospital for routine annual assessment were recruited during the same period. In addition to the aforementioned exclusion criteria, controls were also excluded if they had a history of connective tissue disease, treatment with corticosteroids or antimalarials or immunosuppressives within the last 6 months, known renal impairment (serum creatinine $>110 \mu \mathrm{mol} / \mathrm{l}$ ), or significant proteinuria ( +1 in dipstick or $\geq 500 \mathrm{mg} /$ day in 24-h collection).

Patients and controls gave informed consent that was reconfirmed for the present report, and the University Health Network Research Ethics Board provided approval for the initial and followup studies (UHN/REB: 14-7975 $\mathrm{AE})$.

Methods and study design. Initial characteristics and risk factor documentation have been described previously ${ }^{14}$. Briefly, all participants were assessed for blood pressure at study onset and use of antihypertensive therapy, presence of diabetes and specific therapy, lipid proteins and subfractions, smoking history, body mass index (BMI), waist-hip ratio, metabolic syndrome, history of thyroid disease, menstrual status, and use of oral contraceptives or hormone replacement therapy. Specific questionnaires were used to assess any positive family history for premature CAD (defined as a CAD event before the age of 55 for male and 65 for female first-degree relatives) as well as the level of physical activity [Physical Activity Index (PAI)]. For patients with SLE, SLE Disease Activity Index 2000 (SLEDAI-2K) and the 3-year adjusted mean SLEDAI (AMS; 3 yrs before enrollment up to study entry and between 2005 and 2007) were calculated to quantify overall disease activity. Information on the use of antimalarials, prednisone, and immunosuppressive medications was also collected.

Laboratory measures for all participants included complete blood count, serum creatinine, fasting plasma glucose, CRP, activated partial thromboplastin time, lipid profile [including total cholesterol (TC), TG, HDL, low-density lipoprotein (LDL), very low-density lipoprotein (VLDL), and lipoprotein(a)], and urinalysis. Plasma homocysteine was also measured along with plasma and red blood cell folate levels. In patients only, these were also measured: complement fragments $\mathrm{C} 3$ and $\mathrm{C} 4$, anti-dsDNA antibodies, lupus anticoagulant, and anticardiolipin antibodies ( $\operatorname{IgM}, \operatorname{IgG})$.

Outcome definition. Outcome data regarding patients with SLE were obtained from the Lupus Clinic Oracle database. In case of lost-to-followup patients, most were accessed through telephone interviews and/or responded to pre-established questionnaires; reported events were cross-referenced with the respective Electronic Patient Record. For controls, clinical CVE were documented through telephone interviews and clarified through chart reviews. Outcomes included angina pectoris, acute MI (fatal and nonfatal), TIA, stroke (fatal and nonfatal), and cardiovascular (CV) death; in all occasions atherosclerosis was the underlying cause. Outcome definitions were based upon internationally accepted criteria and have been described previously ${ }^{15}$. For the needs of our present study, we characterized the evolution of risk factors and CV outcomes in 2 different epochs (2000-2007 and 2008-2015).

Statistical analysis. Demographic features of patients with SLE were compared to controls using $t$ test and chi-square test. Categorical classification of Framingham risk factors was determined using currently accepted definitions. For continuous variables, means, SD, and p values are provided In most cases, continuous variables were dichotomized to reflect normal/abnormal levels and compared. The same analysis was performed to establish differences within controls who developed CVE versus those who did not.

Kaplan-Meier cumulative event curve was plotted and stratified according to the presence of SLE. Log-rank test was used to compare the probability of CVE developed over time between patients with and without SLE. A Cox proportional regression model was performed to the role of traditional and disease-related risk factors in relation to the development of CVE. Patients with SLE and controls were included in a single model. Patients were censored as of the time of their last clinic visit or death whereas controls were censored as of the time of last contact or death. Cox proportionality and linearity for continuous variables were satisfied. Stepwise variable selection method was used in the multivariate analysis; $\mathrm{p}$ values were set to 0.15 and 0.10 for variable entry and retention.

\section{RESULTS}

CVE and initial risk factor profile (2000). The findings of the first epoch of the study have been published ${ }^{15}$. Briefly, there were 17/241 (7.1\%) CAD events in the SLE cohort and 5/237 $(2.1 \%)$ in the control population. Independent risk factors identified were SLE, older age at enrollment, and TG $>2.8$ $\mathrm{mmol} / \mathrm{l}$. Followup data, after 15 years, were available for 210 patients with SLE and 138 controls from the initial cohort. Baseline (2000) characteristics are shown in Table 1.

In total (2000-2015), atherosclerotic CVE occurred in $41 / 210$ patients (19.5\%) and 9/138 controls (6.5\%); more than $1 \mathrm{CVE}$ occurred in certain individuals. Angina and MI were simultaneously documented in 4 controls, while 1 patient with SLE developed both MI and stroke. The incidence of CVE was 0.015 events/patient-years for patients with SLE and 0.004 events/patient-years for controls. Coronary artery disease (CAD, angina, and MI) was more common in SLE than controls $(32 / 210,15.2 \%$ vs $5 / 138$,

Personal non-commercial use only. The Journal of Rheumatology Copyright @ $\odot 2017$. All rights reserved 
Table 1. Baseline characteristics of patients and controls in 2000. Values are n (\%) unless otherwise specified.

\begin{tabular}{|c|c|c|c|}
\hline Variables & SLE, $\mathrm{n}=210$ & Controls, $\mathrm{n}=138$ & $\mathrm{p}$ \\
\hline Age at study entry, yrs, mean \pm SD & $44.29 \pm 11.76$ & $44.93 \pm 13.02$ & 0.634 \\
\hline \multicolumn{4}{|l|}{ Race } \\
\hline White & $158(75.2)$ & $123(89.1)$ & 0.013 \\
\hline Black & $24(11.4)$ & $6(4.4)$ & \\
\hline Asian & $13(6.2)$ & $7(5.1)$ & \\
\hline Others & $14(6.7)$ & $2(1.5)$ & \\
\hline Post-menopause & $82(39.0)$ & $39(28.3)$ & 0.039 \\
\hline Family history for CAD & $81(38.6)$ & $58(42.0)$ & 0.519 \\
\hline Arterial hypertension & $67(31.9)$ & $17(12.3)$ & $<0.001$ \\
\hline Diabetes mellitus & $9(4.3)$ & $0(0)$ & 0.036 \\
\hline Dyslipidemia & $67(31.9)$ & $53(38.4)$ & 0.212 \\
\hline Smoking, current & $32(15.2)$ & $22(15.9)$ & 0.710 \\
\hline Physical Activity Index score, mean \pm SD & $37.24 \pm 10.70$ & $41.54 \pm 11.14$ & $<0.001$ \\
\hline Body mass index, mean \pm SD & $24.96 \pm 6.27$ & $25.68 \pm 5.33$ & 0.269 \\
\hline Creatinine, $\mu \mathrm{mol} / 1$, mean $\pm \mathrm{SD}$ & $79.01 \pm 32.60$ & $70.21 \pm 9.47$ & 0.003 \\
\hline Oral contraceptive & $10(4.8)$ & $17(12.3)$ & 0.02 \\
\hline 10-yr Framingham Risk Score, mean \pm SD & $3.09 \pm 3.96$ & $3.43 \pm 4.90$ & 0.485 \\
\hline Followup duration, yrs, mean \pm SD & $13.19 \pm 4.65$ & $15.63 \pm 2.60$ & $<0.001$ \\
\hline
\end{tabular}

SLE: systemic lupus erythematosus; CAD: coronary artery disease.

$3.6 \%, \mathrm{p}=0.0041$ ), whereas there was no statistically significant difference for cerebrovascular disease (TIA and stroke; $10 / 210,4.8 \%$ vs $3 / 138,2.2 \%, p=0.213)$. The mean time for the occurrence of a CVE in patients with SLE was $8.8 \pm 5.2$ years. The probability of CVE development in patients with SLE and controls was statistically different $(p=0.0001$, nonparametric log-rank test). Kaplan-Meier survival curve demonstrated that patients with SLE always had higher rates of CVE, and this difference became greater with longer followup (Figure 1). The actual numbers of CVE that occurred in patients with SLE were 17/241 (7.1\%) between 2000 and 2007 and 24/210 (11.4\%) between 2008 and 2015. In addition, no CVE-related deaths were observed between 2000 and 2007 whereas 10/210 (4.8\%) such deaths occurred between 2008 and 2015 in patients with SLE. No CVE-related death was observed in controls.

Initial risk factor profile revealed a higher prevalence of arterial HTN $(67 / 210,31.9 \%$ vs $17 / 138,12.3 \%$, p < 0.001$)$ and DM $(9 / 210,4.3 \%$ vs $0 / 138,0 \%, \mathrm{p}=0.036)$ in the patient group. Patients also had higher serum creatinine and lower

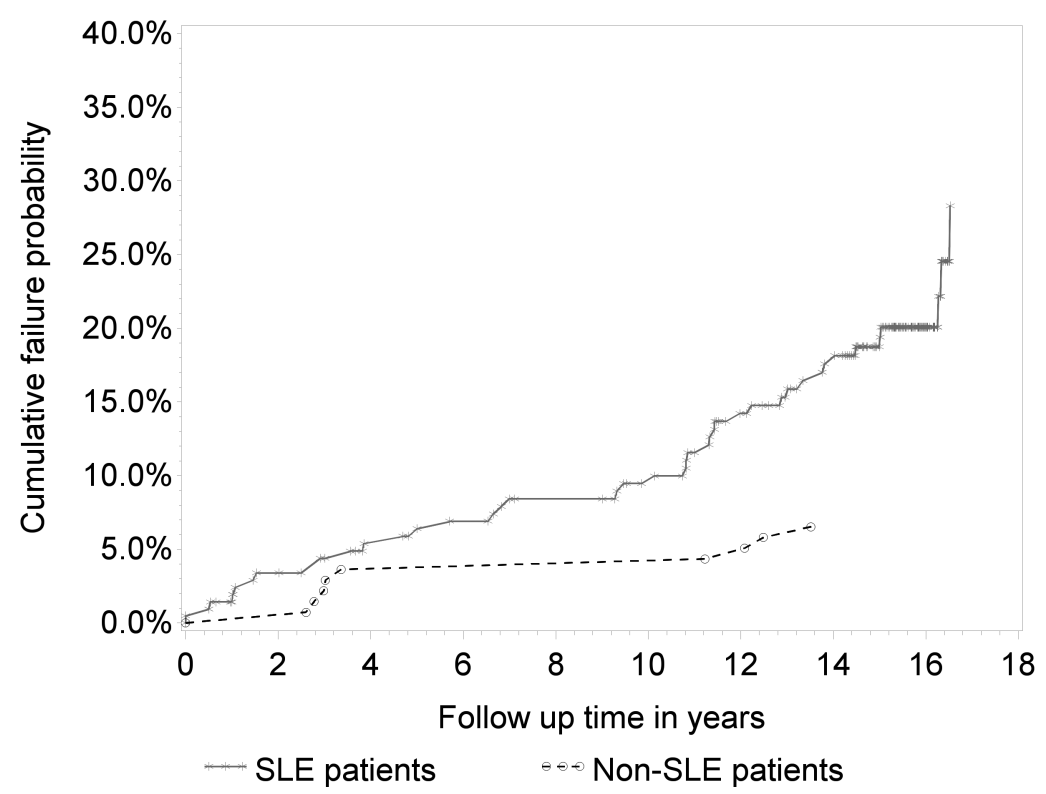

Figure 1. Kaplan-Meier plot for atherosclerotic CVE occurrence in patients and controls Patients with SLE always had higher rates of CVE, the difference becoming greater with longer followup. CVE: cardiovascular events; SLE: systemic lupus erythematosus. 
PAI. On the contrary, proportionally more controls were white and oral contraceptive users. The frequency of other variables did not differ significantly (Table 1). Notably, the prevalence of all traditional risk factors at baseline was highly comparable with the initial cohorts for both patients with SLE and controls ${ }^{14}$.

Traditional and disease-related risk factors by CVE (2000-2007). Further analysis of patients and controls on the basis of CVE development showed that arterial HTN was more frequent in patients and controls who had a CVE (Table 2). Hypercholesterolemia and smoking rates were significantly higher in controls with CVE, while these differences were marginal in patients with SLE. Low levels of HDL were more frequent in SLE patients without CVE. The number of risk factors and the 10-year FRS were higher in both patients with CVE and controls with CVE. Interestingly, disease-related factors positive rate did not differ between SLE patients with CVE and those without (Table 2): the SLEDAI-2K, AMS (3 yrs up to baseline), corticosteroid, antimalarial and immunosuppressive frequency of use, average daily prednisone dose, and antiphospholipid antibodies (aPL; lupus anticoagulant and $\operatorname{IgM}$ and $\operatorname{IgG}$ anticardiolipin antibodies).

Regarding the lipid profile, none of the initially studied variables was found to differ significantly between CVE and non-CVE patients in the SLE group. It should be mentioned that about one-third of SLE patients with CVE were receiving statins at baseline. On the contrary, controls with CVE had higher TC, LDL, VLDL, TG, and CRP.

Multivariate Cox regression analysis for patients and controls covering the entire study period (2000-2015) demonstrated these to be important predictors for CVE in all participants (Table 3): SLE, age at study entry, number of traditional risk factors, VLDL, homocysteine $\geq 15 \mu \mathrm{mol} / 1$, and CRP.

Evolution of traditional and disease-related risk factors (2008-2015). Given that there was no interim assessment of the control population regarding the traditional risk factors, analysis was performed only within the SLE group on the basis of CVE development (Table 4). Apart from increasing age, the prevalence of arterial HTN was significantly increased in the entire SLE cohort as well as the average BMI. The prevalence of diabetes was also increased, although insignificantly. On the contrary, the frequency of other traditional risk factors, such as low HDL, was decreased. The FRS between 2000 and 2008 was only marginally increased (Table 4). Regarding disease-related risk factors, time-adjusted disease activity (as assessed with AMS from 1998-2000 and 2005-2007, respectively) was significantly lower in 2008 while cumulative damage (excluding CV component) was increased.

Patients who had a CVE between 2008 and 2015 were older at 2008 baseline and more frequently had HTN [although mean systolic and diastolic blood pressure (BP), as assessed by the actual measurements of the last 4 clinic visits, did not differ; Table 5]. Interestingly, $60 \%$ of the HTN cases were attributed to corticosteroids because HTN was detected after corticosteroid initiation or a significant increase in prednisone daily dose. Regarding diabetes, there was a significant increase in the CVE group and all these cases were

Table 2. Baseline traditional and disease-related risk factors by outcome in patients and controls (2000-2015). Values are n (\%) unless otherwise specified.

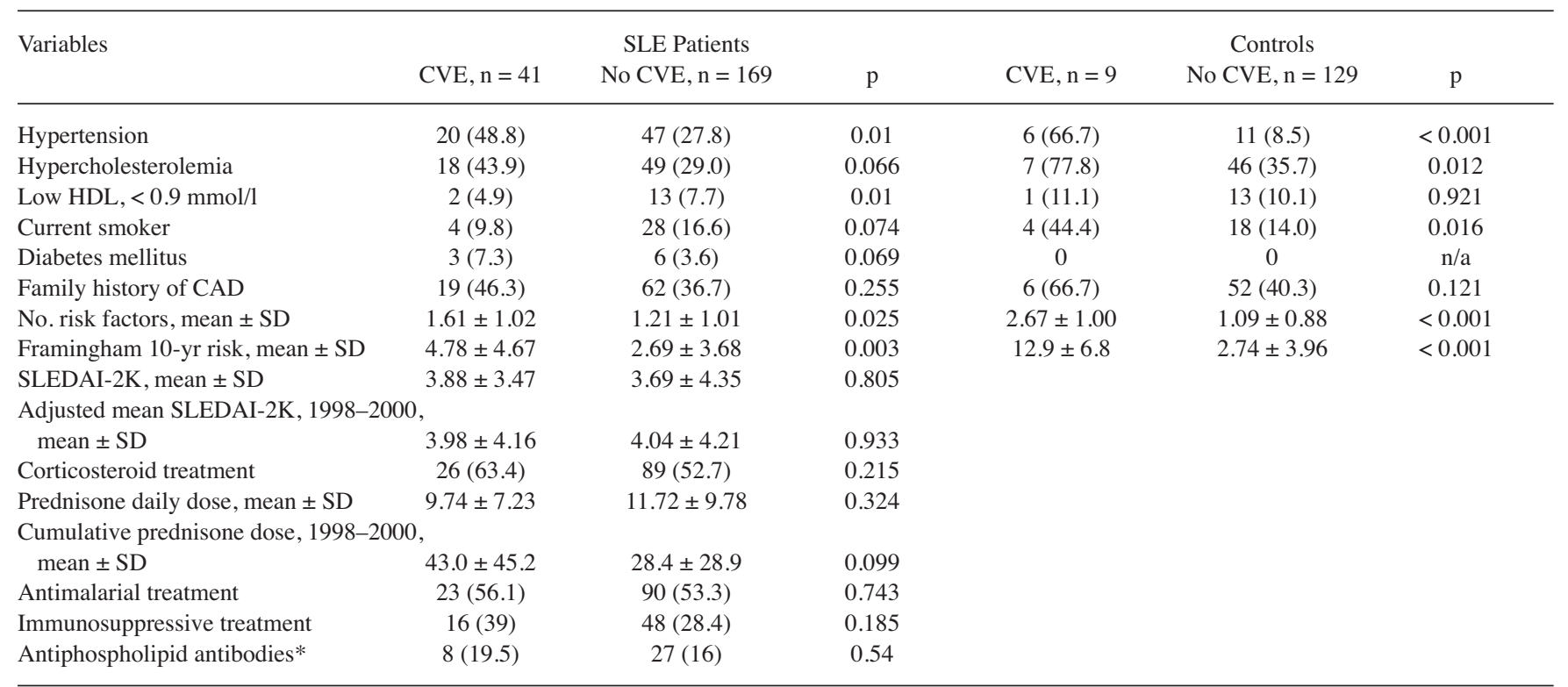

*Antiphospholipid antibodies included lupus anticoagulant and IgM/IgG anticardiolipin antibodies. SLE: systemic lupus erythematosus; CVE: cardiovascular events; HDL: high-density lipoprotein; CAD: coronary artery disease; SLEDAI-2K: Systemic Lupus Erythematosus Disease Activity Index 2000; n/a: not applicable. 
Table 3. Multivariate Cox regression analysis for CVE predictors 2000-2015 (210 patients with SLE and 138 controls).

\begin{tabular}{|c|c|c|c|c|}
\hline Variables & HR & $\begin{array}{l}95 \% \text { Lower } \\
\text { Confidence Limit }\end{array}$ & $\begin{array}{c}95 \% \text { Upper } \\
\text { Confidence Limit }\end{array}$ & $\mathrm{p}$ \\
\hline SLE & 2.82 & 1.27 & 6.28 & 0.011 \\
\hline Age at study entry & 1.06 & 1.03 & 1.09 & $<0.0001$ \\
\hline \multicolumn{5}{|c|}{$\begin{array}{l}\text { No. traditional risk factors (family history of CAD, } \\
\text { diabetes, HTN, hypercholesterolemia, }\end{array}$} \\
\hline low HDL, smoking) & 1.61 & 1.16 & 2.24 & 0.004 \\
\hline VLDL cholesterol & 3.03 & 1.49 & 6.15 & 0.002 \\
\hline Homocysteine $\geq 15 \mu \mathrm{mol} / 1$ & 1.09 & 1.02 & 1.16 & 0.008 \\
\hline CRP & 1.77 & 1.07 & 2.92 & 0.027 \\
\hline
\end{tabular}

CVE: cardiovascular events; SLE: systemic lupus erythematosus; CAD: coronary artery disease; HTN: hypertension; HDL: high-density lipoprotein; VLDL: very low-density lipoprotein; CRP: C-reactive protein.

Table 4. Comparison between the 2 phases of the study (2000-2007 and 2008-2015). Values are $\mathrm{n}(\%)$ unless otherwise specified.

\begin{tabular}{|c|c|c|c|c|}
\hline Variables & $\begin{array}{l}\text { Patients without } \\
\text { CVE, } \mathrm{n}=169\end{array}$ & $\begin{array}{l}\text { Patients with } \\
\text { CVE, } \mathrm{n}=41\end{array}$ & $\begin{array}{l}\text { All Patients, } \\
n=210\end{array}$ & $\mathrm{p}$ \\
\hline Age at $2000, y r s$, mean $\pm S D$ & $43.1 \pm 11.8$ & $49.3 \pm 10.2$ & $44.3 \pm 11.8$ & $<0.0001$ \\
\hline Age at 2008, yrs, mean \pm SD & $51 \pm 12.1$ & $56.8 \pm 10.4$ & $52.1 \pm 12$ & \\
\hline HTN 2000 & $47 / 169(27.8)$ & 20/41 (48.8) & $67 / 210(31.9)$ & \\
\hline HTN 2008 & $35 / 152(23)$ & 26/41 (63.4) & $87 / 193(45.1)$ & $<0.0001$ \\
\hline $\begin{array}{l}\text { High total cholesterol } 2000 \text {, } \\
>5.2 \mathrm{mmol} / 1\end{array}$ & $49 / 169(29.0)$ & 18/41 (43.9) & $67 / 210(31.9)$ & \\
\hline $\begin{array}{l}\text { High total cholesterol } 2008 \text {, } \\
>5.2 \mathrm{mmol} / 1\end{array}$ & $48 / 155(31.0)$ & $16 / 40(40.0)$ & $64 / 195(32.8)$ & 0.106 \\
\hline Low HDL $2000,<1 \mathrm{mmol} / 1$ & $13 / 166(7.8)$ & $2 / 34(5.9)$ & $15 / 200(7.5)$ & \\
\hline Low HDL $2008,<1 \mathrm{mmol} / 1$ & $3 / 149(2.0)$ & $1 / 39(2.6)$ & $4 / 188(2.1)$ & $<0.001$ \\
\hline Diabetes mellitus 2000 & $6 / 169(3.6)$ & $3 / 40(7.5)$ & $9 / 209(4.3)$ & \\
\hline Diabetes mellitus 2008 & $8 / 155(5.2)$ & $7 / 40(17.5)$ & $15 / 195(7.7)$ & 0.132 \\
\hline Smoking, current, 2000 & $28 / 169(16.6)$ & $4 / 40(10)$ & $32 / 209(15.3)$ & \\
\hline Smoking, current, 2008 & $15 / 155(9.68)$ & $2 / 40(5)$ & $17 / 195(8.7)$ & $<0.0001$ \\
\hline Body mass index 2000 & $24.7 \pm 6.0$ & $26.0 \pm 7.2$ & $25 \pm 6.3$ & \\
\hline Body mass index 2008 & $25.4 \pm 5.8$ & $28.6 \pm 7.4$ & $26 \pm 6.2$ & $<0.0001$ \\
\hline Framingham Risk Score 2000 & $2.7 \pm 3.7$ & $4.8 \pm 4.7$ & $3.1 \pm 4.0$ & \\
\hline Median & & & 2.0 & \\
\hline Framingham Risk Score 2008 & $3.5 \pm 3.6$ & $5.6 \pm 4.6$ & $4.1 \pm 2.5$ & 0.0534 \\
\hline Median & & & 3.0 & \\
\hline Serum creatinine $\geq 110 \mathrm{mmol} / \mathrm{l} 2000$ & $10 / 168(6)$ & $7 / 40(17.5)$ & $17 / 208(8.2)$ & \\
\hline Serum creatinine $\geq 110 \mathrm{mmol} / 12008$ & $15 / 155(9.7)$ & $7 / 40(17.5)$ & 22/195 (11.3) & 0.156 \\
\hline Adjusted mean SLEDAI 2000 & $4.0 \pm 4.2$ & $4.0 \pm 4.2$ & $4.0 \pm 4.2$ & \\
\hline Adjusted mean SLEDAI 2008 & $3.2 \pm 2.9$ & $2.8 \pm 2.5$ & $3.1 \pm 2.8$ & 0.0447 \\
\hline \multicolumn{5}{|l|}{ SLICC/ACR DI 2000, excluding } \\
\hline CV component & & & $1.4 \pm 1.7$ & \\
\hline \multicolumn{5}{|l|}{ SLICC/ACR DI 2008, excluding } \\
\hline CV component & $1.8 \pm 1.9$ & $3.05 \pm 2.86$ & $2.1 \pm 2.2$ & $<0.0001$ \\
\hline
\end{tabular}

CVE: cardiovascular events; HTN: hypertension; HDL: high-density lipoprotein; SLEDAI: Systemic Lupus Erythematosus Disease Activity Index; SLICC: Systemic Lupus International Collaborating Clinics; ACR: American College of Rheumatology; DI: damage index.

diagnosed as corticosteroid-induced diabetes. Dyslipidemia was more frequent in the CVE group, although the average levels of HDL and LDL were about the same between groups. In addition, patients with CVE had a higher BMI; their overall FRS was higher (Table 5).
Concerning disease-related risk factors, patients with CVE had a lower, yet insignificantly, global disease activity, but significantly higher cumulative prednisone dose (between 2000 and 2008). These patients had a higher rate of active renal $(14 / 41,34.1 \%$ vs $33 / 169,19.5 \%, \mathrm{p}=0.044)$ and 
Table 5. Traditional and disease-related atherosclerotic risk factors for SLE patients with and without CVE at the 2008 baseline. Values are mean \pm SD unless otherwise specified.

\begin{tabular}{lccc}
\hline Variables & $\begin{array}{c}\text { Patients without } \\
\text { CVE, } \mathrm{n}=169\end{array}$ & $\begin{array}{c}\text { Patients with } \\
\text { CVE, } \mathrm{n}=41\end{array}$ & $\mathrm{p}$ \\
& & & \\
\hline Age, yrs & $50.98 \pm 12.13$ & $56.80 \pm 10.37$ & 0.005 \\
HTN, $\mathrm{n}(\%)$ & $62(36.7)$ & $26(63.4)$ & 0.015 \\
Steroid-induced HTN, n (\%) & $25 / 62(40.3)$ & $15 / 25(60)$ & 0.001 \\
Systolic BP, mmHg & $120.83 \pm 15.15$ & $126.35 \pm 20.60$ & 0.059 \\
Diastolic BP, mmHg & $73.86 \pm 10.15$ & $73.70 \pm 11.11$ & 0.931 \\
Diabetes, $\mathrm{n}(\%)$ & $8(4.7)$ & $7(17.1)$ & 0.006 \\
Steroid-induced diabetes, n (\%) & $4 / 8(50)$ & $7 / 7(100)$ & $<0.001$ \\
Dyslipidemia & $21(12.4)$ & $16(39.0)$ & $<0.001$ \\
Total cholesterol, mmol/1 & $4.76 \pm 0.86$ & $5.21 \pm 1.35$ & 0.011 \\
Triglycerides, mmol/1 & $1.36 \pm 0.76$ & $1.80 \pm 0.92$ & 0.003 \\
HDL, mmol/l & $1.66 \pm 0.48$ & $1.63 \pm 0.49$ & 0.653 \\
LDL, mmol/1 & $2.52 \pm 0.81$ & $2.69 \pm 0.84$ & 0.234 \\
Body mass index & $25.40 \pm 5.80$ & $28.57 \pm 7.45$ & 0.013 \\
$\quad$ Median (IQR) & $24(22-27)$ & $28(23-33)$ & 0.018 \\
Smoking, current, $\mathrm{n}(\%)$ & $15 / 155(9.68)$ & $2 / 40(5)$ & 1.000 \\
Framingham Score 2008 & $2.26 \pm 2.45$ & $3.44 \pm 2.39$ & 0.006 \\
$\quad$ Median (IQR) & $3(0-4)$ & $3(2-5)$ & 0.004 \\
Adjusted mean SLEDAI 2005-2007 & $3.15 \pm 2.85$ & $2.83 \pm 2.55$ & 0.525 \\
$\quad$ Median (IQR) & $3(1-5)$ & $2(1-4)$ & 0.622 \\
SLICC/ACR DI, excluding CVD component & $1.83 \pm 1.91$ & $3.05 \pm 2.86$ & 0.002 \\
$\quad$ Median (IQR) & $1(0-3)$ & $3(1-5)$ & 0.012 \\
Cumulative prednisone dose, g, between 2000 & & & \\
$\quad$ and 2008 & $33.92 \pm 31.45$ & $50.49 \pm 40.88$ & 0.015 \\
Median (IQR) & $24(11-48)$ & $34(20-82)$ & 0.034 \\
SLICC steroid-related 2008 (cataract or muscle atrophy or & & \\
$\quad$ weakness or osteoporosis with fractures & & & \\
$\quad$ or avascular necrosis), n (\%) & $141(83.4)$ & $29(70.7)$ & 0.063 \\
\hline
\end{tabular}

SLE: systemic lupus erythematosus; CVE: cardiovascular events; HTN: hypertension; BP: blood pressure; HDL: high-density lipoprotein; LDL: low-density lipoprotein; IQR: interquartile range; SLEDAI: Systemic Lupus Erythematosus Disease Activity Index; SLICC: Systemic Lupus International Collaborating Clinics; ACR: American College of Rheumatology; DI: damage index; CVD: CV disease.

neuropsychiatric involvement $(7 / 41,17.1 \%$ vs $14 / 169,8.3 \%$, $\mathrm{p}=0.092$ ) during that period (data not shown). Cumulative damage was higher in patients with CVE, although the Damage Index components that are directly linked to longterm corticosteroids (cataract, muscle atrophy, avascular necrosis, and osteoporosis with fractures) were more prevalent in patients who did not develop any CVE (Table 5).

Predictors for all-cause mortality. There were 31 deaths among patients with SLE and 6 among controls. In the SLE cohort, 10 deaths were attributed to $\mathrm{CV}$ causes (6 MI, 2 strokes, 1 cerebral aneurysm, and 1 aortic dissection), 8 to malignancy, 6 to infection, 1 to active SLE, 1 to respiratory failure, and 5 to other causes. For controls, 5 deaths were attributed to malignancy and 1 to infection. Important predictors for all-cause mortality were SLE (HR 4.2, 95\% CI $1.02-17.4, \mathrm{p}=0.04)$, age at study entry (HR $1.09,95 \% \mathrm{CI}$ $1.04-1.14, \mathrm{p}=0.0003$ ), and number of traditional risk factors (HR $2.49,95 \%$ CI $1.28-4.81, \mathrm{p}=0.007)$.

\section{DISCUSSION}

Accelerated atherosclerosis leading to CVE represents one of the major causes of death in SLE, with the respective standardized mortality ratio to be the only one that did not diminish over time ${ }^{17}$. Moreover, a greater relative risk has been demonstrated in younger ages because patients with SLE aged 20-39 years had a 16-fold increased risk of death from CAD in a population-wide study from Sweden ${ }^{18}$. Increased morbidity for CAD has been confirmed even during the first year after diagnosis (relative risk for $\mathrm{MI}=$ $5)^{19}$, as well as 2 years preceding diagnosis ${ }^{20}$.

The pathophysiology of premature atherosclerosis in SLE is incompletely understood and involves complex interactions between traditional and disease-related risk factors ${ }^{21}$. Among the latter, SLE itself confers the greater risk for premature CAD and disease activity, and cumulative damage; certain autoantibodies, soluble inflammatory factors, and medications seem to be involved as well ${ }^{13}$. Nevertheless, the importance of traditional risk factors cannot be underestimated, because early detection and management may improve longterm prognosis.

Several studies have thus far attempted to address the question of which factors can drive CAD development in

Personal non-commercial use only. The Journal of Rheumatology Copyright $@$ 2017. All rights reserved. 
patients with SLE SL, $3,4,22-40$; their usual followup was about 8 years. The major differentiation of the present prospective study was that the average followup period was 13-15 years, covering the first 15 years after menopause, which is reportedly the most dangerous period for atherosclerotic CVE in female patients with SLE. The longterm followup allowed for the evaluation of differences in the relative importance of certain risk factors over time and eventually for timely management of these factors.

Considering the entire duration of our study, the relative risk for atherosclerotic CVE in patients with SLE was increased 4-fold as compared to controls; the difference was more substantial in CAD and not in cerebrovascular disease. In addition, the difference in CVE prevalence increases over time. Several factors were independent predictors of CVE in the combined cohort, such as SLE itself, age at study entry, number of traditional risk factors, VLDL, homocysteine, and CRP.

The concept of SLE as an independent variable for accelerated atherosclerosis is multifactorial. Apart from the well-known role of the aPL, which have been demonstrated to significantly affect $\mathrm{CV}$ risk ${ }^{22,23,25,27,31,35}$, anti-dsDNA antibodies were also implicated ${ }^{31}$. Of note, aPL possibly contribute to the development of CVE by promoting thrombosis on a preexisting plaque rather than being directly involved in the atherosclerotic process. Other factors include renal function impairment ${ }^{25,31}$ and/or proteinuria ${ }^{39,40}$, as well as neuropsychiatric involvement ${ }^{2,22,24}$. Besides the aforementioned variables, the most important, and consistently demonstrated, disease-related risk factors are increased disease activity $22,23,31,32,36$ and cumulative damage $22,27,33$.

In our present study, SLE itself was a powerful predictor for CVE in the first 8 years of the study when the patients' age ranged from 32 to 54 years. However, during the second half of the study, traditional risk factors (HTN, diabetes, dyslipidemia, BMI) became more important because disease activity was significantly decreased. Patients with CVE had been administered a significantly higher cumulative prednisone dose; these patients also had higher rates of corticosteroid-induced HTN and diabetes and they had a higher BMI and higher prevalence of dyslipidemia. Despite adequate control of disease activity (as indicated by the reduction in AMS) and HTN and dyslipidemia (as by the comparable mean systolic and diastolic BP and LDL levels), these patients developed CVE more frequently. Corticosteroids have been demonstrated to increase the burden of CV risk ${ }^{30,31,39}$; other studies, however, did not reach similar conclusions ${ }^{33,38}$. Antimalarials are thought to be protective ${ }^{32,40}$. Corticosteroids are capable of interfering with several biochemical pathways, thus increasing the severity of traditional risk factors, such as glucose and lipoprotein metabolism impairment and blood pressure ${ }^{21}$.

Most of the traditional risk factors were detected in higher frequency in patients and controls who had a CVE, as already described by other investigators ${ }^{2-40}$. Regarding dyslipidemia in particular, there was a higher frequency of elevated cholesterol and TG in patients with CVE, despite statin therapy and achieving LDL and HDL targets (as indicated by the 2008 values). In line with this observation, previous reports have described the role of $\mathrm{TC}^{3,22,32,34,36}$ and $\mathrm{TG}^{15,36}$ in SLE-related accelerated atherosclerosis. Surprisingly, there is no solid evidence that increased LDL is an independent predictor for CVE in patients with $\operatorname{SLE}^{27,33,38}$. This discrepancy, as compared to the general population, may be attributed to the relatively small number of patients and CVE in SLE studies. It has been shown that time-adjusted values of TC are more accurate in predicting CV risk ${ }^{32}$; thus, frequent assessment of lipid profile is important in assessing $\mathrm{CV}$ risk and the need for treatment.

A global assessment of the effect of traditional risk factors on CV risk is achieved through the FRS, a validated tool for the general population. In our study, FRS significantly underestimated CVE in patients with SLE at 2000 baseline (predicted for $10 \mathrm{yrs}=3.1 \%$, actual in $8 \mathrm{yrs}=7.1 \%$ ), as well as at 2008 baseline (predicted for $10 \mathrm{yrs}=4.1 \%$, actual in 8 $\mathrm{yrs}=11.4 \%)$. The explanation is that the FRS relies heavily on age (younger patients have a significantly lower score) and does not take into account the chronic systemic inflammation of SLE. In this context, it was recently demonstrated that a doubling of FRS dramatically increases its accuracy ${ }^{41}$.

The disease itself was found to be a strong predictor of all-cause mortality, conferring a 4-fold increased risk of death, a finding that is in agreement with previous reports ${ }^{42}$. About one-third of deaths in our cohort were attributed to $\mathrm{CV}$ disease; however, it was demonstrated that increased mortality in patients with SLE remains even after adjustment for $\mathrm{CV}$ causes ${ }^{20}$. Nevertheless, the total number of traditional atherosclerotic risk factors was also an independent predictor for all-cause mortality, reflecting their contribution to CVE.

Limitations of our present study are primarily the lost-to-followup patients (16\%) and controls (44.8\%); however, the longterm followup (13-15 yrs) and the fact that controls were healthy women with minimal needs for repeated medical appointments may justify these numbers. Consequently, the evolution of traditional risk factors in controls could only be documented by telephone interview, which has inherent weaknesses. Moreover, the evolution of lipid profile over time has not been documented in controls. It should be noted that novel risk factors for accelerated atherosclerosis, such as certain cytokines and autoantibodies, were not available at inception and therefore could not be followed over time.

SLE-related risk factors drive accelerated atherosclerosis in the early stages of the disease while traditional risk factors, partially attributed to increased cumulative prednisone dose, significantly affect $\mathrm{CV}$ risk in later stages. Thus, as patients survive longer and their disease is better controlled, continued vigilance in monitoring and treating $\mathrm{CV}$ risk factors must remain a priority.

Personal non-commercial use only. The Journal of Rheumatology Copyright $\odot$ 2017. All rights reserved 


\section{ACKNOWLEDGMENT}

The authors thank Arthy Sabapathy, MHSc, for her substantial contribution to data acquisition.

\section{REFERENCES}

1. Urowitz MB, Bookman AA, Koehler BE, Gordon DA, Smythe HA, Ogryzlo MA. The bimodal mortality pattern of systemic lupus erythematosus. Am J Med 1976;60:221-5.

2. Urowitz MB, Ibañez D, Gladman DD. Atherosclerotic vascular events in a single large lupus cohort: prevalence and risk factors. J Rheumatol 2007;34:70-5.

3. Manzi S, Meilahn EN, Rairie JE, Conte CG, Medsger TA Jr, Jansen-McWilliams L, et al. Age-specific incidence rates of myocardial infarction and angina in women with systemic lupus erythematosus: comparison with the Framingham study. Am J Epidemiol 1997;145:408-15.

4. Petri M, Perez-Gutthann S, Spence D, Hochberg MC. Risk factors for coronary artery disease in patients with systemic lupus erythematosus. Am J Med 1992;93:513-9.

5. Nikpour M, Urowitz MB, Gladman DD. Premature atherosclerosis in systemic lupus erythematosus. Rheum Dis Clin North Am 2005;31:329-54, vii-viii.

6. Roman MJ, Shanker BA, Davis A, Lockshin MD, Sammaritano L, Simantov R, et al. Prevalence and correlates of accelerated atherosclerosis in systemic lupus erythematosus. N Engl J Med 2003;349:2399-406.

7. Asanuma Y, Oeser A, Shintani AK, Turner E, Olsen N, Fazio S, et al. Premature coronary-artery atherosclerosis in systemic lupus erythematosus. N Engl J Med 2003;349:2407-15.

8. Svenungsson E, Jensen-Urstad K, Heimburger M, Silveira A, Hamsten A, de Faire U, et al. Risk factors for cardiovascular disease in systemic lupus erythematosus. Circulation 2001;104:1887-93.

9. Doria A, Shoenfeld Y, Wu R, Gambari PF, Puato M, Ghirardello A, et al. Risk factors for subclinical atherosclerosis in a prospective cohort of patients with systemic lupus erythematosus. Ann Rheum Dis 2003;62:1071-7.

10. Kaul MS, Rao SV, Shaw LK, Honeycutt E, Ardoin SP, St Clair EW. Association of systemic lupus erythematosus with angiographically defined coronary artery disease: a retrospective cohort study. Arthritis Care Res 2013;65:266-73.

11. Tselios K, Sheane BJ, Gladman DD, Urowitz MB. Optimal monitoring for coronary heart disease risk in patients with systemic lupus erythematosus: a systematic review. J Rheumatol 2016; 43:54-65.

12. Esdaile JM, Abrahamowicz M, Grodzicky T, Li Y, Panaritis C, Du Berger R, et al. Traditional Framingham risk factors fail to fully account for accelerated atherosclerosis in systemic lupus erythematosus. Arthritis Rheum 2001;44:2331-7.

13. Nikpour M, Gladman DD, Urowitz MB. Premature coronary heart disease in systemic lupus erythematosus: what risk factors do we understand? Lupus 2013;22:1243-50.

14. Bruce IN, Urowitz MB, Gladman DD, Ibañez D, Steiner G. Risk factors for coronary heart disease in women with systemic lupus erythematosus: the Toronto Risk Factor Study. Arthritis Rheum 2003;48:3159-67.

15. Goldberg RJ, Urowitz MB, Ibañez D, Nikpour M, Gladman DD. Risk factors for development of coronary artery disease in women with systemic lupus erythematosus. J Rheumatol 2009;36:2454-61.

16. Hochberg MC. Updating the American College of Rheumatology revised criteria for the classification of systemic lupus erythematosus. Arthritis Rheum 1997;40:1725.

17. Bernatsky S, Boivin JF, Joseph L, Manzi S, Ginzler E, Gladman $\mathrm{DD}$, et al. Mortality in systemic lupus erythematosus. Arthritis Rheum 2006;54:2550-7.
18. Björnådal L, Yin L, Granath F, Klareskog L, Ekbom A. Cardiovascular disease a hazard despite improved prognosis in patients with systemic lupus erythematosus: results from a Swedish population based study 1964-95. J Rheumatol 2004;31:713-9.

19. Avina-Zubieta JA, Sayre EC, Kopec J. Risk of myocardial infarction in patients with systemic lupus erythematosus: a population-based study [abstract]. Lupus 2013;22:20.

20. Bartels CM, Buhr KA, Goldberg JW, Bell CL, Visekruna M, Nekkanti S, et al. Mortality and cardiovascular burden of systemic lupus erythematosus in a US population-based cohort. J Rheumatol 2014;41:680-7.

21. Skaggs BJ, Hahn BH, McMahon M. Accelerated atherosclerosis in patients with SLE - mechanisms and management. Nat Rev Rheumatol 2012;8:214-23.

22. Ballocca F, D'Ascenzo F, Moretti C, Omedè P, Cerrato E, Barbero $\mathrm{U}$, et al. Predictors of cardiovascular events in patients with systemic lupus erythematosus (SLE): a systematic review and meta-analysis. Eur J Preven Cardiol 2015;22:1435-41.

23. Bengtsson C, Ohman ML, Nived O, Rantapää Dahlqvist S. Cardiovascular event in systemic lupus erythematosus in northern Sweden: incidence and predictors in a 7-year follow-up study. Lupus 2012;21:452-9.

24. Bertoli AM, Vilá LM, Alarcón GS, McGwin G, Edberg JC, Petri M, et al. Factors associated with arterial vascular events in PROFILE: a multiethnic lupus cohort. Lupus 2009;18:958-65.

25. Faurschou M, Mellemkjaer L, Starklint H, Kamper AL, Tarp U, Voss A, et al. High risk of ischemic heart disease in patients with lupus nephritis. J Rheumatol 2011;38:2400-5.

26. Gustafsson J, Gunnarsson I, Borjesson O, Pettersson S, Moller S, Fei GZ, et al. Predictors of the first cardiovascular event in patients with systemic lupus erythematosus - a prospective cohort study. Arthritis Res Ther 2009;11:R186.

27. Gustafsson JT, Simard JF, Gunnarsson I, Elvin K, Lundberg IE, Hansson LO, et al. Risk factors for cardiovascular mortality in patients with systemic lupus erythematosus, a prospective cohort study. Arthritis Res Ther 2012;14:R46.

28. Inanc M. Risk factors for non-fatal cardiovascular disease in systemic lupus erythematosus: multivariate analysis in a cohort of 306 patients [abstract]. Lupus 2013.

29. Jolly M, Mikolaitis RA, Block JA, Petri M. Does cigarette smoking affect disease phenotype in systemic lupus erythematosus [abstract]? Arthritis Rheum 2010;62 Suppl 10:S319.

30. Karp I, Abrahamowicz M, Fortin PR, Pilote L, Neville C, Pineau $\mathrm{CA}$, et al. Longitudinal evolution of risk of coronary heart disease in systemic lupus erythematosus. J Rheumatol 2012;39:968-73.

31. Magder LS, Petri M. Incidence of and risk factors for adverse cardiovascular events among patients with systemic lupus erythematosus. Am J Epidemiol 2012;176:708-19.

32. Nikpour M, Urowitz MB, Ibanez D, Harvey P, Gladman DD Importance of cumulative exposure to elevated cholesterol and blood pressure in development of atherosclerotic coronary artery disease in systemic lupus erythematosus: a prospective proof-of-concept cohort study. Arthritis Res Ther 2011;13:R156.

33. Pons-Estel GJ, Gonzalez LA, Zhang J, Burgos PI, Reveille JD, Vilá LM, et al. Predictors of cardiovascular damage in patients with systemic lupus erythematosus: data from LUMINA (LXVIII), a multiethnic US cohort. Rheumatology 2009;48:817-22.

34. Rahman P, Aguero S, Gladman DD, Hallett D, Urowitz MB. Vascular events in hypertensive patients with systemic lupus erythematosus. Lupus 2000;9:672-5.

35. Toloza SM, Uribe AG, McGwin G Jr, Alarcón GS, Fessler BJ, Bastian HM, et al. Systemic lupus erythematosus in a multiethnic US cohort (LUMINA). XXIII. Baseline predictors of vascular events. Arthritis Rheum 2004;50:3947-57.

36. Touma Z, Gladman DD, Ibañez D, Urowitz MB. Ability of 
non-fasting and fasting triglycerides to predict coronary artery disease in lupus patients. Rheumatology 2012;51:528-34.

37. Urowitz MB, Gladman DD. The SLICC inception cohort for atherosclerosis. Curr Rheumatol Rep 2008;10:281-5.

38. Urowitz MB, Gladman D, Ibañez D, Bae SC, Sanchez-Guerrero J, Gordon C, et al; Systemic Lupus International Collaborating Clinics. Atherosclerotic vascular events in a multinational inception cohort of systemic lupus erythematosus. Arthritis Care Res 2010;62:881-7.

39. Wang XY, Tang XQ, Huang YJ, Chen WY, Yu XQ. Frequency of established cardiovascular disease and its risk factors in Chinese patients with systemic lupus erythematosus. Clin Rheumatol 2012;31:669-75.
40. Yang L, Tao J, Tang X, Wang Y, He X, Xu G, et al. Prevalence and correlation of conventional and lupus-specific risk factors for cardiovascular disease in Chinese systemic lupus erythematosus patients. J Eur Acad Dermatol Venereol 2012;26:95-101.

41. Urowitz MB, Ibañez D, Su J, Gladman DD. Modified Framingham Risk Factor Score for systemic lupus erythematosus. J Rheumatol 2016;43:875-9.

42. Merola JF, Bermas B, Lu B, Karlson EW, Massarotti E, Schur PH, et al. Clinical manifestations and survival among adults with (SLE) according to age at diagnosis. Lupus 2014;23:78-84. 